\title{
Estudo do verbo em livros didáticos: excesso permanente de metalinguagens para crianças ${ }^{1}$
}

Wagner Rodrigues Silva²

Ayne Almeida Andrade ${ }^{3}$

Dalve Oliveira Batista-Santos ${ }^{4}$

\section{Resumo}

Investigamos uma proposta de trabalho pedagógico com conteúdo gramatical em uma coleção de livros didáticos para os anos iniciais do Ensino Fundamental, no tocante à classe morfológica dos verbos. Investigamos o manual do professor da coleção selecionada, além dos cinco volumes didáticos destinados aos alunos. Os resultados revelaram que três livros apresentam um trabalho pedagógico sistematizado sobre formas verbais e informado por atividades metalinguísticas. Os verbos são focalizados em textos completos ou, inclusive, em excertos selecionados. As noções de gêneros textuais não influenciaram diretamente o enfoque gramatical, diferentemente do recomendado na literatura científica de referência e em diretrizes curriculares oficiais.

Palavras-chave: Material Didático; Língua Materna; Gramática; Análise Linguística.

\section{Study of verb in textbooks: permanent excess of metalanguages for children}

\section{Abstract}

We investigate a proposal of pedagogical work with grammatical content in a collection of textbooks for the initial years of Elementary School, regarding the morphological class of verbs. We investigated the teacher's manual of the selected collection, in addition to the five didactic volumes intended for students. The results have showed that three books present a pedagogical work systematized on verbal forms and informed by metalinguistic activities. The verbs are focused on full texts or even selected excerpts. The notions of textual genres did not directly influence the grammatical focus, unlike that recommended in the reference scientific literature and in official curricular guidelines.

Keywords: Didactic Material; Mother Language; Grammar; Linguistic Analysis.

\section{Introdução}

O ensino do português como língua materna tem se fundamentado, na maioria das vezes, em preceitos da gramática normativa no contexto escolar brasileiro (MENDONÇA, 2007; TRAVAGLIA, 2009; SILVA, 2011). Esse trabalho pedagógico sobre a referida língua não tem sido suficientemente significativo no tocante ao desenvolvimento de habilidades e competências

\footnotetext{
${ }^{1}$ Este artigo retoma resultados da pesquisa "Perspectivas do estudo do verbo para crianças" (2019), apresentada por Ayne Almeida Andrade como trabalho de conclusão da Licenciatura em Pedagogia. Foi desenvolvida no grupo de pesquisa Práticas de Linguagens - PLES (UFT/CNPq).

${ }^{2}$ Professor Associado IV da Universidade Federal do Tocantins (UFT), Palmas - TO. E-mail: wagnersilva@uft.edu.br

${ }^{3}$ Licenciada em Pedagogia pela Universidade Federal do Tocantins (UFT), Palmas - TO, E-mail: ayne.almeida@gmail.com

${ }^{4}$ Professora Adjunta I da Universidade Federal do Tocantins (UFT), Porto Nacional - TO, E-mail: dalve@uft.edu.br
} 
necessárias à participação dos alunos em diferentes práticas sociais mediadas pela língua(gem) (SILVA, 2012). Faz-se necessário um planejamento de práticas significativas de ensino, contextualizadas e dinâmicas (que tenham continuidade ao longo dos anos escolares), em conformidade com os objetivos idealizados, a exemplo de prescrições curriculares oficiais produzidas em diferentes esferas governamentais.

Algumas pesquisas linguísticas apontam para novos paradigmas de ensino, exigindo de educadores e autores de livros didáticos (LD) para o Ensino Fundamental uma revisão urgente das práticas, conceitos e concepções que possam desencadear novas posturas frente ao ensino da língua materna (SILVA, 2011). Aparício (2010), por exemplo, esclarece que, no Brasil, as discussões sobre o ensino de gramática, as quais são mais perceptíveis a partir da década de 1980, observam desde a validade do ensino até as suas concepções, girando em torno da possibilidade do uso de saberes produzidos no âmbito da ciência linguística para o estudo da gramática na escola. Mais recentemente, esses saberes também informam a Base Nacional Comum Curricular (BNCC) - que prescreve os objetos básicos de conhecimento a serem trabalhados nas práticas de ensino (BRASIL, 2018).

Dentro das mudanças propostas, o LD assume um papel bastante relevante, pois exerce a função de mediador do trabalho do professor em sala de aula. Esse material didático é um recurso bastante utilizado em escolas brasileiras públicas e particulares, portanto, deve estar de acordo com diretrizes curriculares oficiais vigentes, informadas especialmente por abordagens interacionistas, estando o ensino da língua materna orientado por quatro eixos: leitura; produção textual; oralidade; e análise linguística/semiótica (BRASIL, 2018). Conforme detalhado adiante, esse último se configura como uma abordagem produtiva para o trabalho pedagógico sobre diversos aspectos linguísticos, dentre os quais destacamos a gramática do português.

Para tanto, tão importante quanto a mudança de postura do professor diante das recentes teorias linguísticas, estão os materiais didáticos mediadores do ensino. O livro didático de Língua Portuguesa (LDLP) tem passado por transformações no sentido de acompanhar mudanças propostas por diversas teorias linguísticas, sendo alvo de investigações científicas, especialmente por parte de linguistas aplicados (SILVA, 2011; SIGILIANO; SILVA, 2017; BATISTASANTOS; TELES, 2018). Segundo essas investigações, esses materiais podem "maquiar" velhas teorias ou práticas, a exemplo do uso de textos como pretexto para o ensino de gramática. 
O LD pode ser um facilitador/mediador na produção do conhecimento, porém, no âmbito escolar, o livro era e, por vezes, ainda é constituído como um manual a ser seguido, utilizado como se fosse um livro sagrado que o professor deve seguir para a "transmissão" de conteúdos programados. É importante esclarecer que a noção de "transmissão" do conhecimento faz parte de teorias de aprendizagem passadas, nas quais os alunos eram meros "recipientes" - ou segundo Freire (2007, p.66) "'vasilhas', [ou] em recipientes a serem 'enchidos' pelo educador" das ideias alheias. Essas se opõem à ideia de que o conhecimento é construído, o professor é mediador do processo de ensino, e o aprendizado é fruto de um conjunto de reflexões e de relações entre os atores humanos e não humanos no espaço social em que estão integrados.

Considerando que o processo de ensino-aprendizagem se configura e reconfigura por meio de ações reflexivas, investigamos a proposta de trabalho pedagógico com conteúdo gramatical na coleção de LD "Português: linguagens", 6a edição, de autoria de Willian Roberto Cereja e Thereza Cochar Magalhães (2017a; 2017b), para o Ensino Fundamental I, no tocante à classe morfológica dos verbos. Para tanto, descrevemos, especificamente, a proposta de trabalho com o referido conteúdo gramatical, apresentada no manual do professor e, efetivamente, operacionalizada nas unidades didáticas componentes da coleção selecionada.

\section{Estudo de gramática em textos}

O estudo gramatical tem sido fonte de diversas discussões e estudos, uma vez que ainda há dúvidas sobre os métodos e ferramentas de ensino para trabalho com práticas de AL. Souza e Ladeia (2018) atestam que, por vezes, o ensino da Língua Portuguesa (LP) não privilegia a própria língua e o processo contínuo de comunicação, ou seja, compreender e refletir como e por que ocorrem determinados usos linguísticos, acabando por supervalorizar o ensino prescritivo de conteúdos gramaticais.

Embora o ensino de gramática seja um objeto recorrente de pesquisa (MENDONÇA, 2007; TRAVAGLIA, 2009; SILVA, 2011; BATISTA-SANTOS; TELES, 2018), o assunto traz muitas dúvidas a professores, especialmente sobre como, o que e quando trabalhar os distintos objetos de ensino, além da progressividade desses tópicos nos diferentes anos escolares, principalmente no Ensino Fundamental I, que reúne profissionais egressos da Licenciatura em Pedagogia, com uma 
formação linguística bastante restrita diante de demandas do ensino de língua em sala de aula. Esse fato reforça a necessidade da disponibilização de materiais didáticos com qualidade e adequados a professores e alunos ${ }^{5}$, bem como a necessidade de discussões sobre a reformulação dos projetos pedagógicos - especificamente os componentes curriculares oferecidos - de tal curso visando atender às demandas impostas no agir desse profissional - como por exemplo, lecionar múltiplas disciplinas. Mesmo não sendo foco direto da presente discussão, enfatizamos as implicações da formação inicial desses profissionais nas análises realizadas.

Há uma concepção equivocada entre o conhecimento da língua portuguesa e da gramática, associando a esta última uma 'autoridade máxima' na compreensão daquela, inclusive por parte de professores. O principal objetivo do estudo da língua materna é promover o desenvolvimento da capacidade de comunicação, e a gramática reúne saberes que podem auxiliar este processo; assim, ambas são complementares em um processo mais amplo. No entanto, observa-se o uso da gramática normativa como destaque. O estudo da LP vai além do 'certo e errado' (concepções de linguagem enquanto expressão do pensamento e instrumento de comunicação) ${ }^{6}$, engloba um conjunto de práticas sociais atravessadas pela compreensão da dinamicidade dos textos e da capacidade de leitura, escrita e oralidade de variados textos moldados por gêneros.

A gramática normativa sempre foi encarada como conjunto de regras que deveriam ser seguidas, adotadas pelos LD, e que, lendo e relendo essas regras, decorando-as, os alunos aprenderiam de forma competente a norma padrão. Porém, essa prática tornou o ensino mecânico e descontextualizado. Com o passar dos anos, notou-se que o ensino da língua materna não se esgotava ou se satisfazia apenas no modelo repetitivo de escrita e leitura, ambos se completam para que os discentes possam compreender os contextos históricos e sociais vivenciados. Essa é a questão que circunda a discussão de como ensinar a gramática.

\footnotetext{
${ }^{5}$ A Licenciatura em Pedagogia é responsável pela formação de profissionais que, de alguma forma, precisam ser polivalentes, uma vez que são habilitados para ministrar aulas de quaisquer disciplinas escolares para o Ensino Fundamental I. Nos termos de Libâneo (2017, p.70), destacamos que os referidos profissionais "precisam dominar conhecimentos e metodologias de conteúdos muito diferentes como português, matemática, história, geografia, ciências e, às vezes, artes e educação física", mas "não recebem esses conteúdos específicos em sua formação, enquanto os professores dos anos finais, preparados em licenciaturas específicas, passam quatro anos estudando uma só disciplina, aquela em que serão titulados. É impossível este paradoxo não provocar estragos no sistema de formação para os Anos Iniciais".

${ }^{6}$ Essas concepções priorizam "um ensino [de LP] com foco na metalinguagem, isto é, a língua como objeto neutro, homogêneo e desvinculado do sujeito" (BATISTA-SANTOS; TELES, 2018, p.109).
} 
O conceito de gramática pode variar. A gramática normativa descreve a língua num dado momento histórico em função da explicitação de formas legitimadas de uso da língua. Compromete-se com a descrição de regras e conceitos, resultando num criterioso trabalho com metalinguagens. O material didático é um manual de regras a serem observadas por quem deseja se expressar conforme o padrão nele descrito e legitimado (bem falar e escrever). Prioriza-se a língua escrita, sem dar muita importância à modalidade oral, por considerá-las faces da mesma moeda (TRAVAGLIA, 2009). Já a gramática descritiva é responsável pela "descrição da estrutura e funcionamento da língua, de sua forma e função", sem interesses prescritivos (TRAVAGLIA, 2009, p.27), esta gramática é conhecida como a "gramática dos linguistas" e pode se configurar uma abordagem mais produtiva para proporcionar práticas pedagógicas de reflexão sobre o funcionamento do sistema linguístico. Por fim, a gramática internalizada é considerada como "o conjunto das regras que o falante de fato aprendeu e das quais lança mão ao falar" (TRAVAGLIA, 2009, p.28).

Nesse sentido, ao concebermos a gramática em uma perspectiva analítico-reflexiva, excluímos a possibilidade de aulas meramente expositivas, arraigadas de metalinguagens, ao contrário, construímo-la com atividades que provocam os alunos, estimulando-os rumo à descoberta de elementos linguísticos, refletindo sobre a língua (concepção de linguagem enquanto interação ${ }^{7}$ ), ou seja, não é repasse de conhecimento, mas um laboratório de construção do conhecimento com o apoio do professor.

Essa abordagem - de modo analítico-reflexivo da gramática - terá como ponto de partida o trabalho com textos moldados por gêneros. Por isso, se o texto, em seu universo tipológico e de gêneros, for utilizado em parceria com o ensino reflexivo da gramática, numa concepção linguística analítica, é possível que os discentes adquiram um novo olhar sob a perspectiva gramatical, percebendo, então, que essa prática trabalha a funcionalidade e os sentidos produzidos de usos linguísticos em situações interativas, não forjadas, além de perceber que os aspectos morfológicos e sintáticos são também flexíveis, isto é, ajustam-se de acordo com o contexto. Essa percepção só será possível a partir de uma reflexão gramatical.

É relevante conceber a diferença entre o estudo e o ensino de gramática mediada por

\footnotetext{
${ }^{7}$ Nessa concepção, a "linguagem é, pois, um espaço de interação verbal na construção de efeitos de sentidos entre os interlocutores em uma das diversas situações de comunicação" (BATISTA-SANTOS; TELES, 2018, p.111).
}

Periódico Horizontes - USF - Itatiba, SP - Brasil - e021013 
textos. Nesse sentido, Silva (2011) expressa que o ensino de gramática é utilizado para uma abordagem prescritiva nas aulas de língua materna, em outras palavras, o ensino ocorre a partir de exercícios mecânicos, que analisam apenas partes, como palavras e frases. 0 autor compreende o estudo de gramática como:

Atividades didáticas em que o trabalho de mediação do professor leva o aluno a analisar os usos e, consequentemente, os efeitos de sentido expressos por elementos linguísticos em situações interativas reais, nas modalidades falada e escrita da língua. O enfoque dos elementos linguísticos em situações de uso pressupõe o texto como unidade exclusiva de análise. Para essas atividades de estudo de gramática, os modelos semióticos, construídos sócio historicamente, denominados de gêneros textuais, também precisam ser considerados (SILVA, 2011, p.18).

O estudo de gramática é, portanto, amplo quanto aos elementos e às possibilidades. Não precisa se limitar a partes do texto, pode ser focalizado em sua completude, considerando o gênero responsável pelo enquadramento textual. Não é que o estudo de gramática não considere a abordagem normativa, mas precisa ir além dessa concepção, isto é, esse ensino também deve possibilitar reflexões, por parte dos educandos, sobre os efeitos de sentidos que tais 'regras' produzem em textos situados em contexto diversos.

Numa perspectiva enunciativa, a utilização da língua, tanto oral quanto escrita, é construída em forma de enunciados, que refletem condições e finalidades das esferas ou domínios da atividade humana. Assim, a junção da temática, do estilo verbal (recursos lexicais, fraseológicos e gramaticais) e da construção composicional origina gêneros discursivos, na perspectiva enunciativa bakhtiniana (BAKHTIN, 2000).

Numa perspectiva textual, Marcuschi (2008) expressa que os gêneros textuais são representações históricas das variadas atividades comunicativas, não classificáveis de forma fácil em virtude de sua dinamicidade e complexidade. Assim, "os gêneros têm uma identidade e eles são entidades poderosas que, na produção textual, nos condicionam a escolhas que não podem ser totalmente livres e aleatórias, seja sob o ponto de vista do léxico, grau de formalidade ou natureza dos temas" (2008, p.156).

Ainda nos termos do autor, "os gêneros são dinâmicos, de complexidade variável e não sabemos ao certo se é possível contá-los todos, pois, como são sócio históricos e variáveis, não 
há como fazer uma lista fechada, o que dificulta ainda mais sua classificação" (MARCUSCHI, 2008, p.159). Essas estruturas são socialmente reconhecidas, pois se repetem em nosso cotidiano como convenções culturais, com características comuns, procuram atingir intenções semelhantes e ocorrem em situações específicas.

Continuando na perspectiva dos estudos textuais, ressaltamos que os gêneros se realizam em textos compostos pelos denominados tipos textuais (narração, argumentação, exposição, descrição, injunção). Esses indicam um tipo de construção teórica que é "definida pela natureza linguística de sua composição \{aspectos lexicais, sintáticos, tempos verbais, relações lógicas, estilo\}. O tipo caracteriza-se muito mais como sequências linguísticas \{sequências retóricas\} do que como textos materializados; a rigor, são modos textuais" (MARCUSCHI, 2008, p.154), ou seja, configuram-se na forma como o texto se apresenta, não podendo ser confundido com o gênero textual. Considerar os tipos de textos nas práticas de análise linguística pode ser uma estratégia produtiva para o trabalho reflexivo sobre a gramática da língua, conforme demonstrado por Silva (2011), em uma proposta pedagógica de estudo sobre a gramática do português em textos injuntivos (ou instrucionais).

É importante conceber que a gramática - e, portanto, o estudo dos verbos que nos interessa mais de perto neste artigo - não está aquém dos textos. Conforme Travaglia (2011, p.11), “os textos só são produzidos e compreendidos graças à gramática da língua, portanto, não há como trabalhar com textos sem trabalhar a gramática e vice-versa, já a gramática da língua só funciona em textos". Retomando os tipos textuais, pontuamos, por exemplo, que os verbos de ação, em tempos e modos particularizados, caracterizam as narrativas, ao passo que os verbos de estado caracterizam a descrição. Ambos os tipos se integram (e ainda com outros) com distintas funcionalidades em gêneros particularizados.

Os verbos correspondem a um grupo de palavras com funções semelhantes: representam ações físicas (quebrar, vender), mentais (pensar, gostar), comportamentais (sorrir, dormir) e realizações de falas (dizer, gritar), além de existências (existir, haver) e caracterizações (ser; parecer) (HALLIDAY; MATTHIESSEN, 2014). Esses diferentes sentidos e funções podem ser considerados em abordagens pedagógicas. As formas verbais constituem-se de distintas particularidades, ganhando diferentes formas linguísticas (a partir da flexão verbal) para expressar tempos (passado, presente e futuro), aspectos (perfeito, imperfeito, mais-que-feito) e 
modos (indicativo, subjuntivo, imperativo) de realização de fatos textualizados, dentre outros sentidos - gênero, número, pessoa, estado, voz (BECHARA, 2000).

Numa perspectiva normativa, de acordo com Bechara (2000, p.209), o verbo pode ser definido como sendo "a unidade de significado categorial que se caracteriza por ser um molde pelo qual organiza o falar seu significado lexical". Essa definição parece enfatizar a função central da referida categoria gramatical, pois outras formas linguísticas são organizadas no sistema de transitividade a partir das verbais. Numa abordagem mais pedagógica, o autor concebe o verbo como "a unidade que significa ação ou processo, unidade esta organizada para expressar o modo, o tempo, a pessoa e o número" (BECHARA, 2010, p.192).

Defendemos uma abordagem dos verbos que se inicie pela compreensão dos usos em contextos, partindo-se de textos, propondo uma análise dos sentidos situados manifestos pelas referidas formas morfológicas, na situação interativa encapsulada no gênero textual, a partir do qual são materializados tipos textuais particulares.

O ensino de língua marcado por uma sequência de conteúdos gramaticais tomando como base a metodologia tradicional, marcada pelo uso de frases soltas e descontextualizadas, configura-se como uma artimanha para se ensinar a gramática, ignorando-se os textos moldados por gêneros. Santos, Mendonça e Cavalcante (2007, p.28) afirmam que "o funcionamento da língua não se dá em unidades isoladas como fonemas, morfemas ou palavras soltas, mas em unidades maiores: os textos".

Silva (2011, p.43-44) define o texto como "o resultado da confluência do conjunto de recursos, mecanismos e princípios gramaticais utilizados para produzir efeitos de sentido. Texto é a gramática em funcionamento". Com isso, é perceptível que o texto é o objeto central de trabalho do professor de língua portuguesa, pois é a partir dele que o aluno compreenderá os gêneros textuais e a gramática. Realçando motivações contextuais em textos falados ou escritos, Halliday e Hasan (1976, p.293-294) afirmam que

Qualquer linguagem que seja operacional, funcionando como uma unidade em algum contexto de situação, constitui um texto. Pode ser falado ou escrito, em qualquer estilo ou gênero, e envolvendo qualquer número de participantes ativos. Geralmente, ele exibe uma forma de consistência que é definida pelo conceito de registro: uma consistência nos estilos de significado ou tipos de configuração semântica que incorporam sua relação com seu ambiente. Em outras palavras, um texto é geralmente razoavelmente homogêneo, pelo

Periódico Horizontes - USF - Itatiba, SP - Brasil - e021013 
menos nos aspectos linguísticos que mais de perto refletem e expressam sua relação funcional com seu ambiente ${ }^{8}$.

Santos, Mendonça e Cavalcante (2007, p.29) afirmam que "todos os textos se organizam como gêneros textuais típicos, que usamos para contextos determinados social e historicamente, a partir de estratégias interativas construídas na sociedade em que estamos inseridos". Nesse enunciado, também percebemos a ideia do estudo contextualizado pautado numa abordagem interacionista, ou seja, a construção do conhecimento em sintonia com a gramática em sua amplitude, com os alunos e com o ambiente.

A unidade de análise em aulas de LP é o texto, considerado os gêneros como objetos de ensino. Assim, a metodologia mais viável é explorar o estudo da gramática por meio do texto, seja em sua produção escrita, interpretação ou práticas de oralidade, trazendo para a sala de aula um novo conceito de ensino: a análise linguística $(A L)$.

A AL vem se popularizando e se tornando uma realidade e prática pedagógica por parte dos professores de LP nos últimos anos, em virtude da possibilidade de alcançar resultados mais precisos dentro e fora da sala. Silva $(2011$, p.30) nos fala que a principal característica da AL é o estudo de gramática a partir da reflexão sobre os elementos textuais: "o estudo de gramática no nível do texto, diferentemente da abordagem da tradição do ensino gramatical, nos níveis da frase e da palavra, é a principal característica da atividade de análise linguística". Nessa perspectiva, o texto é compreendido como ponto de 'partida e chegada' para o trabalho pedagógico nessa concepção de AL. Conforme proposto por Franchi (1987), salientamos que há situações em que não se pode ignorar o trabalho de análise a partir de unidades linguísticas inferiores ao texto.

Em conformidade com Mendonça (2007), a AL também não pode ser confundida com a gramática contextualizada, no sentido de utilizar um texto como pretexto, pois essa última se difere minimante da gramática tradicional, ressaltando que, para evitar mal-entendidos, é preciso deixar claro que a "AL não significa apenas uma mudança de métodos, mas sim uma

\footnotetext{
8 "Any piece of language that is operational, functioning as a unity in some context of situation, constitutes a text. It may be spoken or written, in any style or genre, and involving any number of active participants. I will usually display a form of consistency that is defined by the concept of register: a consistency in the meaning styles or type of semantic configuration which embody its relation to its environment. In other words, a text is usually reasonably homogeneous, at lest in those linguistic aspects which most closely reflect and express its functional relationship to its setting".
} 
outra concepção do que seja a linguagem e do que deve ser o seu ensino" (p.76). Em suma, a base da AL é o pressuposto de que a linguagem não é uma estrutura fixada (dada, acabada, ou seja, com a utilização de regras), mas é uma forma de interação social, em que o mais importante é refletir as necessidades dos alunos, com a utilização de atividades que possibilitem a criação, análise e interpretação dos textos.

Por fim, complementamos que, em seus esforços para inovar o trabalho pedagógico com a gramática, Franchi (1987) aponta a existência de três atividades com e sobre a língua, as quais influenciaram inúmeras propostas curriculares oficiais: (1) linguística, que faz uso de atividades com o exercício pleno, intencionado em direção a significância da própria linguagem, que ocorre naturalmente no cotidiano do aluno, com sua família e comunidade e somente se reproduz na escola por meio da interação social; (2) epilinguística, essa é a prática consciente do uso da linguagem, com variações dos recursos formais e progressivos, observando os efeitos de sentidos produzidos a partir dos usos das formas gramaticais; e (3) metalinguística, caracterizada com o uso de atividades que procuram falar sobre a língua dando nomes e definindo as categorias linguísticas.

\section{Considerações metodológicas}

Este estudo se desdobra na forma de uma pesquisa de revisão bibliográfica, como base para a realização de uma análise documental exploratória e reflexiva. Assumimos uma abordagem predominantemente qualitativa, pois analisamos os livros selecionados à luz da literatura científica mobilizada, sem pretensão alguma de conciliar uma abordagem quantitativa. Como instrumento orientador do exame dos documentos, utilizamos uma ficha analítica para mapear o trabalho gramatical proposto sobre as formas verbais nos cinco volumes integrantes da coleção de LD. A referida ficha foi reproduzida no Quadro 1, localizado na seção seguinte deste artigo. Esse instrumento nos permitiu identificar os seguintes aspectos caracterizadores do trabalho pedagógico proposto nos LD: (i) ocorrência do trabalho sobre verbos (volume, unidade e capítulo); (ii) aspecto focalizado da classe gramatical (conceito, concordância, tempo, dentre outros); (iii) categorização funcional do enfoque (articulação a práticas de leitura e escrita ou trabalho restrito ao própria tópico gramatica); e (iv) dimensão da unidade linguística (exemplificação com excertos ou textos completos). 
Este estudo foi desenvolvido em duas principais etapas instauradas, ainda que, em algumas situações, procedimentos característicos das diferentes etapas tenham ocorrido simultaneamente: (1) revisão bibliográfica a partir do confronto entre pressupostos teóricometodológico de Franchi (1987), Mendonça (2007), Marcuschi (2008), Travaglia (2009; 2011), Silva (2011), dentre outros. Realizamos um breve percurso sobre a análise linguística como foco no estudo de gramática, perpassando por algumas concepções de gramática, verbo, texto, gênero e análise linguística (HALLIDAY; HASAN, 1976; HALLIDAY; MATTHIESSEN, 2014); e (2) exame dos cinco volumes da coleção selecionada de LD. Os esclarecimentos teóricometodológicos apresentados no manual do professor foram considerados e contrastados com a implementação pedagógica nos volumes didáticos.

Além de apresentar o modo como os objetos de ensino estão distribuídos dentro dos LD, o manual do professor revela a base teórico-metodológica sobre a qual a coleção foi produzida. Essas informações foram essenciais para verificarmos possíveis relações entre pressupostos teórico-metodológicos dos estudos linguísticos e a proposta pedagógica apresentada no manual do professor para o ensino/estudo da gramática.

Realizamos uma análise exploratória da coleção de LD "Português: Linguagens", 6ạ edição, de William Roberto Cereja e Thereza Cochar Magalhães (2017a; 2017b) para o Ensino Fundamental I. A coleção foi selecionada por termos conhecimento da boa receptividade dos materiais didáticos produzidos pelos referidos autores em escolas brasileiras de ensino básico, o que inclui os LD produzidos pelos mesmos autores para o Ensino Fundamental II e Ensino Médio. Para tanto, com base na pesquisa bibliográfica a respeito do estudo da gramática, investigamos os volumes do $3^{\circ}$ ao $5^{\circ}$ ano, com foco no ensino/estudo da gramática a partir de atividades que focalizam a classe gramatical dos verbos.

A seleção dos referidos volumes se justifica por não termos encontrado o enfoque das formas verbais nos livros do $1^{\circ}$ e $2 \circ$ anos. O primeiro volume é voltado para a alfabetização, o que justifica o enfoque nas convenções do sistema alfabético-ortográfico da língua portuguesa. O segundo volume continua o trabalho do livro anterior, enfatiza-se o trabalho com convenções ou regras ortográficas e inicia-se o ensino de classes morfológicas a partir do trabalho com substantivos.

O manual do professor está organizado em seis seções, começando pela Introdução, seguida por Pressupostos teóricos e metodológicos; Avaliação; Estrutura e metodologia da obra; 
Cronograma; e Sugestões de estratégias e recursos. Na Introdução, é possível identificar a perspectiva teórico-metodológica adotada pela coleção: apoia-se na metodologia, segundo os autores, "sociointeracionista de aprendizagem com um enfoque no enunciativo da língua". Essa abordagem se desenvolve a partir da "leitura de textos verbais e não verbais, de produção de textos - centrada em gêneros orais e impressos e multimodais - e de reflexão sobre a língua e a linguagem" (CEREJA, MAGALHÃES, 2017b, p.4).

No manual do professor, os autores discorrem que a concepção e a organização da coleção têm como "proposta de ensino de produção de texto a partir dos gêneros do discurso ou gêneros textuais" (CEREJA; MAGALHÃES, 2017b, p.12). Expressam, ainda, que "o texto vem ganhando o papel de unidade de ensino nas aulas de Português, isto é, vem se transformando no principal objeto de ensino dessa disciplina" (p.22). Assim, a coleção, segundo os autores, adota o estudo de gramática a partir do texto como objeto central de estudo e reflexão acerca da língua materna, junto a crianças do Ensino Fundamental I - 10 ao 5o ano. Para os autores:

Por meio deste trabalho, o aluno depara como papel de certos componentes gramaticais - os pronomes, os advérbios, as preposições e as conjunções - na estruturação de textos. A finalidade é, portanto, levar o aluno a operar esses conceitos no nível do texto, e não formalizá-los. Não há, pois, nenhuma intenção de descrever a língua como um objetivo em si. (CEREJA; COCHAR, 2017b, p.23).

A escolha do objeto de pesquisa se justifica por nosso interesse em contribuir com discussões especializadas em torno do trabalho gramatical pedagógico, em especial com encaminhamentos sobre o estudo dos verbos em aulas de LP. Pontuamos algumas posturas passíveis de assunção por professores em função de usos mais sustentáveis ou proveitosos do LD como aliado de alunos e educadores em sala de aula (e, certamente, pais ou responsáveis no acompanhamento das atividades escolares das crianças nos lares). Conforme mostraremos na seção seguinte deste artigo, o texto é o ponto de partida para a introdução do tópico gramatical focalizado neste estudo.

\section{Análise do material didático}

A análise do material didático se deu inicialmente com o entendimento do conteúdo 
trabalhado em cada capítulo integrante das quatro unidades que compõem cada volume da coleção. No Quadro 1, caracterizamos as ocorrências do trabalho pedagógico com formas verbais, inseridas na seção o Reflexão sobre a linguagem. Além da identificação do volume, unidade e capítulo da ocorrência, mostramos o enfoque atribuído à categoria, que perpassa a conceituação, a concordância e os tempos verbais. Realçamos o trabalho com duas desinências verbais caracterizadoras das formas verbais no pretérito (-ram) e futuro perfeitos (-rão) e da terceira pessoa do plural. Essas desinências são bastante confundidas na escrita do português, especialmente por crianças. A sequência do conteúdo se complexifica ao longo dos anos, chegando ao enfoque dos verbos irregulares no 5ㅇ ano.

No Quadro 1, registramos duas tendências da abordagem do conteúdo gramatical quanto ao propósito: articulação a práticas de leitura ou escrita e restrita ao própria tópico linguístico, garantindo-se, respectivamente, o conhecimento das formas verbais em função de usos linguísticos imediatamente explícitos ou como saber gramatical legitimado culturalmente, passível de aproveitamento pelos alunos em outras situações. Quanto à dimensão na unidade de análise para o tratamento das formas verbais, oscila entre textos completos ou excertos selecionados a partir textos previamente trabalhados, mesmo que sua integridade seja ignorada ao serem retomados nas práticas de análise linguística. Salientamos que, especialmente em tarefas propostas, é frequente o uso de frases descontextualizadas.

Quadro 1 - Mapeamento do enfoque das formas verbais

\begin{tabular}{|c|c|c|c|c|}
\hline ANO & $\begin{array}{l}\text { UNIDADE } \\
\text { CAPÍTULO }\end{array}$ & ENFOQUE & $\begin{array}{l}\text { CATEGORIZAÇÃO } \\
\text { FUNCIONAL }\end{array}$ & $\begin{array}{c}\text { DIMENSÃO } \\
\text { TEXTUAL }\end{array}$ \\
\hline 3음 & U3 C2 & Conceito de verbo & Compreensão textual & Completo \\
\hline 30 & U3 C2 & Conceito de verbo & $\begin{array}{l}\text { Identificação } \\
\text { em dicionário }\end{array}$ & $\begin{array}{l}\text { Completo } \\
\text { Excerto }\end{array}$ \\
\hline 30 & U3 C3 & Concordância verbal & Exemplificação gramatical & $\begin{array}{l}\text { Completo } \\
\text { Excerto }\end{array}$ \\
\hline 40 & U1 C3 & Tempos verbais & Exemplificação gramatical & Excerto \\
\hline 40 & U1 C3 & Tempos verbais & Produção textual & Completo \\
\hline 40 & U1 C3 & Tempos verbais & Compreensão textual & Completo \\
\hline 40 & U1 C3 & Concordância verbal & Exemplificação gramatical & Excerto \\
\hline 40 & U1 C3 & -ram x -rão & Exemplificação gramatical & Completo \\
\hline 5은 & U3 C2 & Concordância verbal & Compreensão textual & $\begin{array}{l}\text { Completo } \\
\text { Excerto }\end{array}$ \\
\hline 5응 & U1 C2 & Verbos irregulares & Compreensão textual & Completo \\
\hline
\end{tabular}


A atividade do Exemplo 1, pertencente ao $3^{\circ}$ ano, encontra-se disposta no Capítulo 2. Há um cartum e perguntas que objetivam levar os alunos a interpretação quanto às "ações" que o personagem central desempenha de forma explícita ou implícita no texto. A atividade é proposta para construir o conceito de verbo com os alunos, o qual só é apresentado ao final (todas as palavras que estão nos balões do cartum expressam ações que as pessoas fazem na vida: amar, errar, agradecer, perdoar, perder, etc. Palavras que expressam ações são chamadas de verbos).

No gênero cartum, o uso de imagens é essencial na composição textual, mesclam-se as linguagens verbal e não verbal (linguagem multimodal $\left.{ }^{9}\right)$. O gênero textual escolhido é adequado em razão da faixa etária dos alunos, pois são compartilhados elementos que auxiliam a compreensão textual e podem prender a atenção das crianças. A atividade cumpre o objetivo de trabalhar a categoria verbal a partir do conceito de "ação", presente especialmente nos diferentes enunciados que compõem a primeira questão (Observe o desenho de cada quadrinho e o pensamento da personagem Gaturro em cada um deles. Cada palavra do cartum indica uma ação.). Em todas as questões da atividade, a fisionomia do personagem (Gaturro), em cada quadro, retoma o verbo descrito no balão correspondente.

\footnotetext{
${ }^{9}$ Segundo Barros (2009, p.163), "para a semiótica social, o texto escrito per si é multimodal, isto é, também se compõe por mais de um modo de representação. [Num texto], por exemplo, além da linguagem escrita, outras formas de representação, como a diagramação, a qualidade do papel, o formato e a cor das letras, entre outros elementos, contribuem e interferem nos sentidos dos textos. Dessa forma, nenhum sinal ou código pode ser entendido em sua amplitude quando estudado isoladamente, já que os elementos se complementam na composição dos sentidos".
} 
Exemplo 1 - 3ㅇ ano do Ensino Fundamental

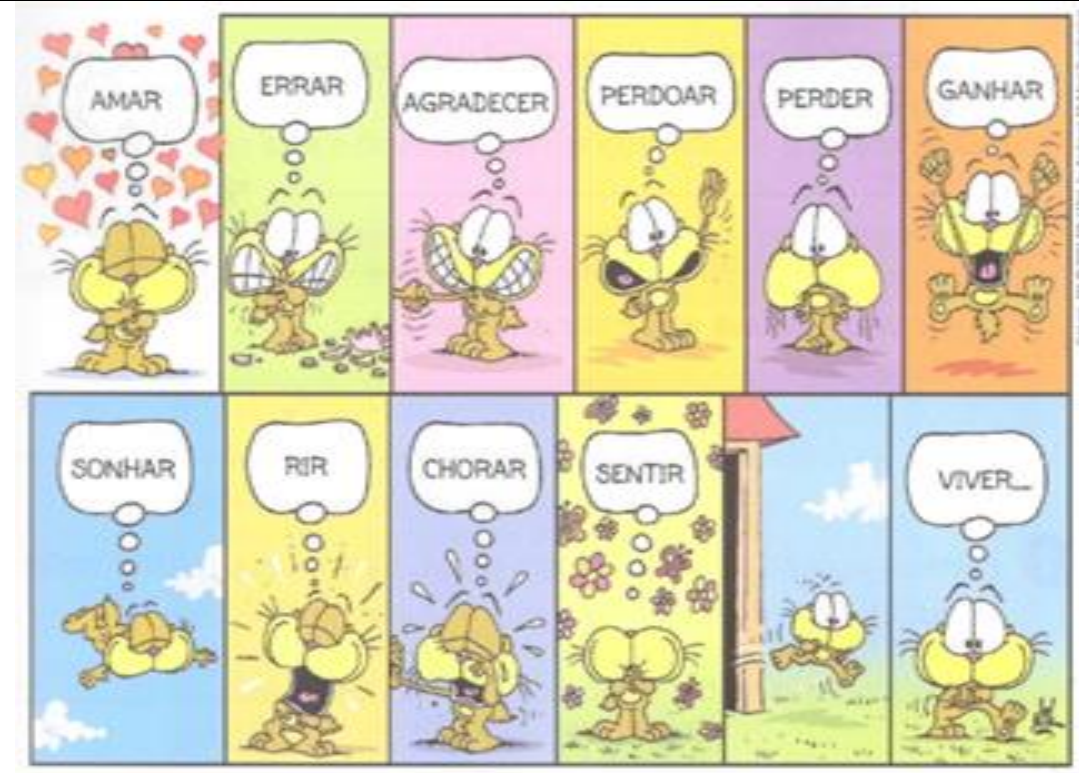

Wak. Goturro Buenos Aires: Ediciones de La Flor, 2012. ₹. 18, p. 53)

O VERBO

Leia o cartum:

[texto reproduzido acima]

1 Observe o desenho de cada quadrinho e o pensamento da personagem Gaturro em cada um deles. Cada palavra do cartum indica uma ação.

a) Gaturro fica alegre ao pensar em quais ações? Escreva:

R: ganhar e rir

b) Gaturro fica muito triste ou decepcionado ao pensar em quais ações? Escreva:

$R$ : perder e chorar

c) Gaturro fica sentimental ou sensível ao pensar em quais ações? Escreva:

R: amar e sentir

d) Gaturro fica leve ao pensar em qual ação? Escreva:

$R$ : sonhar

2 Entre as ações nas quais Gaturro pensa, há uma que resume todas as outras. Qual é ela? Escreva:

R: viver

3 De acordo com o cartum, a vida é cheia de que tipo de fatos e ações?

( ) alegres ( ) tristes $(x)$ variados, isto é, às vezes bons, às vezes ruins

R: Todas as palavras que estão nos balões do cartum expressam ações que as pessoas fazem na vida: amar, errar, agradecer, perdoar, perder, etc. Palavras que expressam ações são chamadas de verbos.

Os verbos podem também indicar estado. Por exemplo:

Gaturro está feliz.

Gaturro ficou triste.

As palavras está e ficou são verbos que indicam o estado de Gaturro.

Verbos são palavras que indicam ação e estado.

Fonte: Cereja e Magalhães (2017a, p.213-214).

O texto traz as bases para a reflexão sobre a categoria gramatical, demandando a compreensão pelo leitor, o que fica evidente na segunda e terceira questões. Tal reflexão parte de ações cotidianas representadas na fisionomia do personagem e registradas em palavras. Vale 
ressaltar, ainda, que a atividade segue uma sequência de: preparação sobre o assunto; construção em conjunto da base para o conceito; e apresentação do conceito, que pode ser um momento de avaliação do discutido anteriormente. Vejamos o exemplo a seguir.

No Exemplo 2, reproduzimos uma questão da subseção "Brincando com palavras", originária da Unidade 1, Capítulo 3, do volume do 4ㅇano. Outro uso dado ao mesmo texto do 3o Ano, reproduzido no Exemplo 1, justificou nossa escolha para exemplificação.

Exemplo $2-4$ ano do Ensino Fundamental

5 Leia a tira.

(Nik. Gaturro. Buenos Aires: Ediciones de La Flor, 2012. V.18, p.53. Tradução dos autores.)

[texto do Exemplo 1]

Imagine que Gaturro, a personagem da tira, estivesse se lamentando com frases do tipo:

- Eles nunca me amaram...

- Eles nunca erraram..

Como ficariam os outros verbos da tira, nesse possível lamento de Gaturro? Escreva as formas verbais.

$R$ : Eles nunca agradeceram/perdoaram/perderam/ganharam/sonharam/riram/choraram/sentiram /viveram... Professor: Se quiser, você pode propor que este exercício seja realizado oralmente. Se preferir, pode também pedir as formas verbais no futuro, em contraposição ao passado: Eles nunca me amaram... / Eles nunca me amarão.

Fonte: Cereja e Magalhães (2017a, p.74).

Conforme mostramos no Exemplo 1, o enfoque do tópico gramatical pode auxiliar na compreensão textual, ou seja, o cartum é focalizado em toda sua dimensão (verbal e não-verbal), resultando numa prática de análise linguística relevante, ainda que se desdobre na construção conceitual junto a crianças com idade entre nove e dez anos ${ }^{10}$. Trata-se de uma questão muito próxima do que compreendemos por atividade epilinguística, pois a ênfase recai sobre o efeito de sentido a ser provocado com trabalho sobre a estrutura da língua, ainda que proposta a partir de uma situação fictícia presente no texto de referência.

No Exemplo 2, por sua vez, o texto foi utilizado como pretexto para proporcionar aos alunos a compreensão e fixação do uso da desinência "-ram". As formas verbais no infinitivo nominal dos balões do texto de referência são utilizadas para que os alunos elaborem frases no pretérito perfeito, conforme o modelo apresentado com os verbos dos dois primeiros balões.

\footnotetext{
${ }^{10}$ Registramos que, na coleção de LD, há uma oscilação na classificação do gênero do texto selecionado. No LD do 3 ano, o texto é referido como cartum, ao passo que, no 4ㅇ ano, é retomado como tira. Não nos interessa aprofundar uma discussão sobre essas nomenclaturas, mas esse tipo de oscilação deve ser evitado quando se tratam de nomes utilizados para gêneros diferentes, ainda que haja alguma proximidade entre eles.
} 
Ressaltamos a sugestão dada ao professor para solicitar que os alunos produzam as frases oralmente (Se quiser, você pode propor que este exercício seja realizado oralmente.) e, conforme queira o profissional, podendo treinar ainda o uso da desinência "-rão", responsável pelo futuro perfeito, na terceira pessoa do plural (Se preferir, pode pedir as formas verbais no futuro, contrapondo ao passado). A repetição oral de frases não se configura como uma efetiva prática de oralidade, conforme proposta em diretrizes oficiais e literaturas científicas (BRASIL, 2018; MAGALHÃES; LACERDA, 2019).

Os autores da obra também se valem do resgate de fragmentos de textos lidos previamente para auxiliar na conceituação do verbo. Isso ocorre nas atividades examinadas nos LD do $3^{\circ}$ ao $5^{\circ}$ ano. O Exemplo 3, reproduzido do volume do 40 ano, evidencia o trabalho dessas atividades.

Exemplo 3 - 4ㅇa ano do Ensino Fundamental

TEMPOS VERBAIS - A CONCORDÂNCIA DO VERBO COM O SUJEITO COMPOSTO

TEMPOS VERBAIS

Releia este trecho da carta pessoal que você leu:

"Minha mãe manda perguntar se vocês poderão vir ao Rio no aniversário da vó Luiza, em julho. Nossos parentes de Goiânia já confirmaram. Eles chegarão no dia 10 e vão passar o fim de semana aqui".

Observe que, nesse trecho da carta, os verbos se referem a fatos relacionados a três tempos diferentes: passado, presente e futuro.

\section{Retomando o conceito de verbo}

Verbo são palavras que expressam ação e estado.

Em "As aulas já começaram”, a forma verbal começaram expressa ação.

Em “como estão as coisas por aí?", a forma verbal estão expressa estado.

1 Qual dos verbos indica algo que está ocorrendo no presente, ou seja, no momento em que Fernando está escrevendo a carta?

$R:$ manda

2 Qual dos verbos indica algo que aconteceu no passado?

$R$ : confirmaram

3 Quais dos verbos indicam algo que vai acontecer no futuro?

R: poderão, chegarão

4 Reescreva as frases, passando o verbo, que está no presente, para o passado e para o futuro.

Veja o exemplo:

Hoje, os familiares chegam. (presente)

Ontem, os familiares chegaram. (passado)

Amanhã, os familiares chegarão. (futuro)

a) Hoje, eles passeiam na orla de salvador. R: Ontem, eles passearam... / Amanhã, eles passearão...

b) Hoje, as pessoas saem para fazer compras.

R: Ontem, as pessoas saíram... / Amanhã, as pessoas sairão...

c) Hoje, as aulas estão suspensas.

R: Ontem, as aulas estiveram suspensas. / Amanhã, as aulas estarão suspensas.

Professor: Chame a atenção dos alunos para a grafia das formas do passado, terminadas em -ram, e as formas do futuro, terminadas em -rão.

Fonte: Cereja e Magalhães (2017a, p.63-64). 
No Exemplo 3, são focalizados os tempos verbais. Diferentemente da atividade do Exemplo 1, em que o enfoque verbal se mostra atrelada à compreensão textual, os tempos verbais são trabalhados num excerto focalizado independentemente da totalidade do texto fonte, que foram trabalhados previamente no capítulo. Nas três primeiras questões, o enfoque se restringe à identificação de verbos em tempos específicos no excerto transcrito (1. Qual dos verbos indica algo que está ocorrendo no presente, ou seja, no momento em que Fernando está escrevendo a carta?; 2. Qual dos verbos indica algo que aconteceu no passado?; 3. Qual dos verbos indica algo que aconteceu no futuro?). Na questão quatro, o trabalho de reescrita de frases em diferentes tempos verbais está desarticulado de textos de referência (4. Reescreva as frases, passando o verbo, que está no presente, para o passado e para o futuro.). Essa questão se alinha à abordagem do Exemplo 2, isto é, um ensino pautado na metalinguagem gramatical, sem possibilitar ao aluno alguma reflexão sobre o efeito de sentido promovido por tempos verbais em situações interativas situadas.

No 3을 ano, identificamos atividades com excertos reproduzidos de outro texto previamente trabalhado. Também são utilizados para focalizar a concordância verbal a partir da reescrita de frases ignorando-se o conteúdo do texto de referência (1. Reescreva os quatro primeiros versos desse trecho da canção, trocando a expressão "Todo rato" por "Todos os ratos" e adaptando o que for necessário. Depois, responda: $O$ que aconteceu com os verbos?; 2. Reescreva os três últimos versos desse trecho, trocando a expressão "os ratos" por "o rato" $e$ adaptando o que for necessário. Depois, responda: O que aconteceu com os verbos?). Destacamos a visibilidade dada à metalinguagem, pois, para trabalhar a concordância, é conceituada a categoria de sujeito (O sujeito de uma oração é a parte sobre a qual se fala alguma coisa. Sujeito é também o elemento com o qual o verbo concorda.), que envolve a sintaxe da língua portuguesa.

Nestas atividades, a gramática não é focalizada em função do gênero textual, mas se trabalha o tópico gramatical selecionado, que pode ser útil para o público-alvo do material didático, que, por vezes, apresenta demanda pelo enfoque da concordância verbal em produções escritas. Porém, destacamos que são questões voltadas para o nível da estrutura gramatical, exigindo-se das crianças a identificação e classificação de categorias gramaticais de acordo com conceitos teóricos explanados no livro. Conforme problematizado por Franchi 
(1987), essas atividades são caracterizadas como metalinguísticas. Do nosso ponto de vista, a metalinguagem poderia ser evitada no Ensino Fundamental I, quando se espera que as crianças passem a se interessar por práticas de leitura e escrita, além de desenvolver uma predisposição interessada por parte dessas crianças para refletir sobre o funcionamento gramatical do português, em diferentes manifestações da língua, resultando numa conscientização linguística.

No Ensino Fundamental I, há um enfoque no processo de aprendizado da leitura e escrita, por isso, muitos livros contemplam atividades nesse sentido. Não é necessário um trabalho com nomenclaturas gramaticais de modo tão explícito, a abordagem pode ser realizada na perspectiva da AL. Portanto, as atividades metalinguísticas para os alunos nessa faixa etária e desenvolvimento podem se configurar como um exercício enfadonho e desmotivador, com um nível de complexidade elevado e carregado de teorias que poderiam ser trabalhadas de forma mais branda ou indireta e atingindo objetivos sustentáveis.

No Exemplo 4, a concordância verbal também é focalizada nas atividades do livro didático do $5^{\circ}$ ano, bem como o ensino pautado na metalinguagem. Tomemos o exemplo a seguir.

Exemplo 4 - 5o ano do Ensino Fundamental
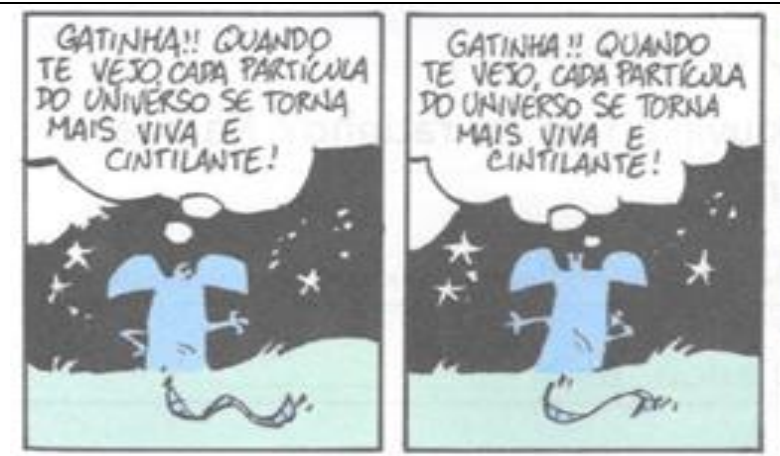
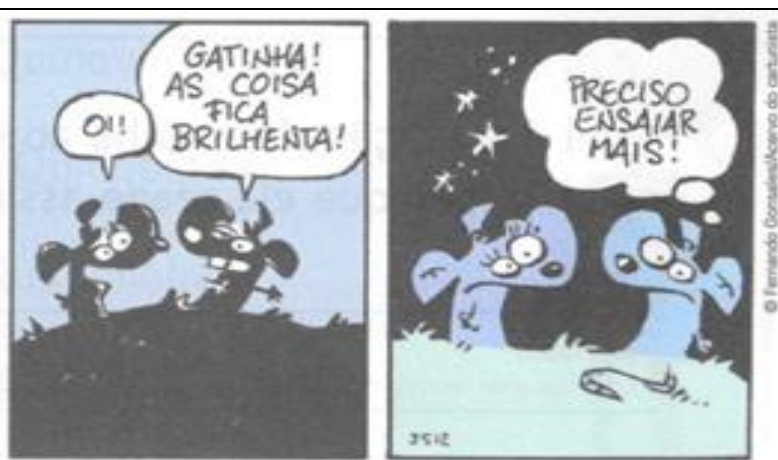

(Vá pentear macacosl. Săo Paulo: Devir, 2004. p. 29.)

A CONCORDÂNCIA VERBAL

Você aprendeu, no 3ํ e no 4ำ ano, que o verbo de uma oração precisa estar em concordância com o sujeito. Vamos, neste capítulo, retomar esse assunto e aprofundá-lo um pouco mais.

Leia esta tira, de Fernando Gonsales:

[texto reproduzido acima]

10 que o ratinho está fazendo nos dois primeiros quadrinhos?

R: Ele está ensaiando uma declaração de amor que pretende fazer para a ratinha.

2 Observe a fala do ratinho no 30 quadrinho. Ele conseguiu falar o que tinha preparado? Por quê?

R: Não; porque ele se atrapalhou na presença da ratinha.

3 A fala do ratinho apresenta alguns desvios gramaticais.

a) Reescreva a frase, corrigindo esses desvios.

R: Gatinha! As coisas ficaram brilhantes!

b) Na frase corrigida, o verbo ficar aparece no singular ou no plural? Explique a razão dessa concordância. R: Está no plural, porque o sujeito é o termo As coisas. 
Lembre-se

Reveja alguns conceitos que você aprendeu no 3o ano e no 4ㅇaㅁ

Sujeito é a parte da oração sobre a qual se afirma alguma coisa; predicado é ao que se afirma sobre o sujeito.

Sujeito simples é o que apresenta um único núcleo; sujeito composto é o que apresenta dois ou mais núcleos.

O verbo, que faz parte do predicado, deve estar em concordância com o sujeito.

4 Qual é a reação da ratinha ao ouvir a fala do ratinho? Na sua opinião, por que ela reage assim?

$R$ : A ratinha não entende e estranha o que o ratinho fala, pois a frase dele não tem sentido e, além disso, apresenta problemas gramaticais, o que a surpreende.

O princípio básico da concordância verbal é: o verbo deve estar em concordância com o sujeito.

A coisa fica brilhante.

As coisas ficam brilhantes.

5 No texto da história de Chapeuzinho Vermelho que você leu no início deste capítulo, o caçador diz à Vovó:

- Fui eu, dona Quinquinhas.

Observe que, nessa frase, a forma verbal fui está em concordância com o pronome pessoal eu, que é o sujeito da oração. Ambos estão na 1a pessoa do singular.

a) Como ficaria o verbo ser, caso tivéssemos as seguintes alterações na frase?

- Fomos nós, dona Quindinhas.

- Foi você, dona Quindinhas.

- Foi ele, dona Quindinhas.

- Foram eles, dona Quindinhas.

- Foste tu, dona Quindinhas.

b) Conclua: Em cada frase alterada, qual é o sujeito?

$R: E ́$ o pronome que vem depois do verbo: nós, você, ele, eles e tu, respectivamente.

Fonte: Cereja e Magalhães (2017a, p.203-205)

Conforme dito no enunciado inicial da atividade do Exemplo 4, são retomadas metalinguagens trabalhadas em anos anteriores, o que resulta numa escrita bastante técnica para o público a que se destina (Você aprendeu, no 3o e no 4o ano, que o verbo de uma oração precisa estar em concordância como sujeito. Vamos, neste capítulo, retomar esse assunto e aprofundá-lo um pouco mais.). Também são retomados os conceitos de sujeito (é a parte da oração sobre a qual se afirma alguma coisa), predicado (é o que se afirma sobre o sujeito), sujeito simples (é o que apresenta um único núcleo) e sujeito composto (é o que apresenta dois ou mais núcleos). Isso revela a reiteração de uma abordagem metalinguística ao longo dos anos escolares.

A explicitação desses conceitos demanda algum posicionamento crítico do professor ${ }^{11}$, haja vista o uso excessivo de metalinguagem, quando, na realidade, poderiam ser enfatizadas atividades epilinguísticas, familiarizando as crianças com práticas de reflexão sobre a língua em função dos efeitos de sentido construídos por escolhas gramaticais e lexicais. Assim, evita-se a já

\footnotetext{
11 Como dito anteriormente, mesmo não sendo foco da nossa investigação, faz-se necessário promovermos discussões e investigações que tenham como temática a formação do professor dos anos iniciais para o trabalho com AL nas aulas de LP.
} 
conhecida reprodução de representações indesejadas ou negativas em torno do português como língua materna, vista por inúmeros alunos como objeto de estudo maçante, portanto, desinteressante.

Embora as atividades sejam relevantes para os alunos aprenderem usos padronizados da língua, a exemplo da concordância verbal, a simples aplicação de regras não garante um aprendizado reflexivo e crítico. Em outras palavras, faz-se necessária a criticidade do professor, pois a atividade em questão prioriza a correção linguística, ignorando aspectos contextuais, os quais determinam ou justificam algumas escolhas linguísticas, mesmo usos que escapem à abordagem normativa da língua.

A primeira e segunda questões ( $O$ que o ratinho está fazendo nos dois primeiros quadrinhos?; Observe a fala do ratinho no 3o quadrinho. Ele conseguiu falar o que tinha preparado? Por quê?) focalizam precariamente a compreensão textual necessária para garantir respostas críticas por parte dos alunos, diante da situação interativa representada na tirinha. A abordagem prescritiva e limitada da atividade se torna mais evidente nas duas questões subsequentes (A fala do ratinho apresenta alguns desvios gramaticais. Reescreva a frase, corrigindo esses desvios. Na frase corrigida, o verbo ficar aparece no singular ou no plural? Explique a razão dessa concordância).

O enunciado ' $a$ ' da terceira questão solicita a reescrita da fala do personagem, sem problematizar as razões que levam os sujeitos a realizarem diferentes registros da língua e, em muitas ocasiões, a não aplicarem a concordância verbal da norma dita padrão. Nos dois primeiros quadrinhos, por exemplo, as convenções legitimadas de concordância verbal foram observadas, mas, posteriormente, por fatores emocionais, tal observância gramatical escapou ao personagem. Podemos afirmar, nesse sentido, que a resposta apresentada para a quarta questão pode contribuir para fortalecer preconceitos em torno de pessoas que não se utilizam da variedade linguística legitimada ( $A$ ratinha não entende e estranha o que o ratinho fala, pois a frase dele não tem sentido e, além disso, apresenta problemas gramaticais, o que a surpreende.). Será que o desvio da norma padrão, a exemplo da não observância da concordância verbal, impossibilita a compreensão textual? Certamente, a ausência de concordância não será um empecilho para um interlocutor receptivo à situação interativa instaurada. Para atividades desse tipo, faz-se necessária a complementação da abordagem 
por professores, evitando-se, inclusive, que alguns alunos reconheçam e assumam representações estigmatizadas sobre variedades linguísticas utilizadas por familiares ou por eles mesmos.

Por isso, o professor necessita de compreensão e consciência sobre o que e como é trabalhado o conteúdo e necessita também se posicionar em relação às atividades de modo a conseguir trabalhar a AL e minimizar a ênfase na metalinguagem. Franchi $(1987$, p.43) explana que o professor, baseando-se em sua sensibilidade e intuição, pode explorar a questão, mesmo que seja uma simples oração, pois há "inúmeras possibilidades de um exercício gramatical diretamente relacionado com as condições linguísticas de produção dos enunciados, com o desenvolvimento dos recursos expressivos dos alunos", filtrando o que é importante e direcionando para o alcance do objetivo.

Ainda, no Exemplo 4, vislumbramos uma prática recorrente na coleção de didáticos: a construção de definições ou conceitos gramaticais ao longo das questões, a exemplo do que descrevemos no Exemplo 1. Na quinta questão do Exemplo 4, é retomada uma frase da História da Chapeuzinho Vermelho para exemplificar a concordância com o sujeito pronominal posposto à forma verbal (Como ficaria o verbo ser, caso tivéssemos as seguintes alterações na frase? nós, Dona Quinquinhas; você, Dona Quinquinhas; ele, Dona Quinquinhas; eles, Dona Quinquinhas; tu, Dona Quinquinhas). A partir do enfoque da concordância verbal, mais uma vez o metaconhecimento da sintaxe do português é demandado dos alunos. A questão ' $b$ ' focaliza a identificação das formas pronominais como sujeitos das respectivas frases listadas (Conclua: em cada frase alterada, qual é o sujeito?), conforme observado na resposta (é o pronome que vem depois do verbo).

A análise da coleção de LD nos mostrou uma predominância de atividades direcionadas para o trabalho orientado pela metalinguagem, pois o foco é a conscientização das crianças sobre o funcionamento e as categorizações da gramática normativa do português. Silva (2011) alerta que um enfoque excessivo e desnecessário das atividades metalinguísticas pode comprometer o trabalho sobre a materialidade e a funcionalidade textual, que deveria ser útil nas atividades de escrita e leitura. 


\section{Considerações finais}

Em distintos contextos de instrução formal, a prática de AL se configura em perspectivas diversas. Na coleção de LD analisada, foi caracterizada por atividades compostas por uma sequência de questões responsáveis por construções conceptuais graduais. Em outras palavras, a explicitação de conceitos ou definições acontece ao final da sequência de questões integrantes da tarefa, após possibilitar ao aluno a experiência de reflexão sobre aspectos gramaticais do português, ainda que as questões propostas sejam atravessadas por metalinguagens. Essa ordem de sequenciamento das atividades diverge da tradição escolar. Nessa última, apresenta-se um conceito gramatical, seguido por exemplificações e, finalmente, acompanhado por exercícios de fixação. Faz-se necessário ressaltar, ainda, a diversidade de gêneros utilizada nos livros investigados, mesmo estes sendo utilizados, na maioria das vezes, como pretexto nas atividades gramaticais.

Chamou-nos a atenção, porém, o significativo uso da metalinguagem gramatical nas atividades propostas para crianças com faixa etária entre oito e onze anos, as quais ainda estão se apropriando do gosto pela leitura e escrita e ainda compreendem a escola como mais um espaço para brincadeiras, em meio à privilegiada socialização com os colegas. Resta-nos a curiosidade a respeito da recepção e eficácia da prática descrita junto às crianças do Ensino Fundamental I. Essa curiosidade só pode ser sanada com uma pesquisa de campo, a qual fica como sugestão para nossos leitores ou como empreitada a assumirmos futuramente.

O uso verificado da metalinguagem pode se configurar como 'um risco' para a prática do professor e, consequentemente, formação discente. A tradição escolar já mostrou que as aulas de LP foram responsáveis pela precária formação de falantes e escritores do português, muitos dos quais frustrados pelo repetitivo e insustentável ensino dos mesmos tópicos gramaticais nos diferentes níveis da educação básica - Ensino Fundamental I, Ensino Fundamental II e Ensino Médio (podendo até mesmo ser revisitado de forma fracassada no Ensino Superior). Os professores, por sua vez, trazem em suas lembranças esse mesmo ensino gramatical da tradição escolar, o qual tende a ser a única referência diante da fragilidade da formação linguística em um curso com currículo genérico - Licenciatura em Pedagogia. Nesse sentido, a coleção investigada pode sinalizar para os professores o livre percurso para reprodução da prática pouco produtiva que lhes é familiar.

Periódico Horizontes - USF - Itatiba, SP - Brasil - e021013 
Urge uma ressignificação dos currículos dos cursos de Pedagogia, proporcionando aos licenciandos embasamento linguístico para que possam atuar de maneira reflexiva, crítica e significativa na sala de aula, especificamente nas aulas de LP. Aos alunos da escola básica, é necessário possibilitar uma reflexão sobre os efeitos de sentidos que as regras gramaticais produzem no/pelo texto, em atividades de natureza epilinguística.

Por fim, destacamos a importância do investimento na produção de bons livros didáticos, pois, por vezes, são os únicos recursos disponíveis aos professores em sala de aula. Ademais, realçamos a relevância de pesquisas em torno desses materiais didáticos (e da formação de professores), pois, além de poderem influenciar a produção dos mesmos, podem servir de referência para o estudo de professores em exercício e, inclusive, para os professores em formação inicial.

\section{Referências}

APARÍCIO, A. S. M. Modos individuais e coletivos de produzir a inovação no ensino de gramática em sala de aula. Revista Brasileira de Linguística Aplicada, Belo Horizonte, v.10, n.4, p.883-907, 2010.

BAKHTIN, M. Estética da criação verbal. 3. ed. São Paulo: Martins Fontes, 2000.

BARROS, C. G. P. Capacidades de leitura de textos multimodais. Polifonia, Cuiabá, n.19. p.161186. 2009.

BATISTA-SANTOS, D. O; TELES, E. A. Concepções de gramática no livro didático: interfaces com o ensino de língua materna. Interfaces. Guarapuava, v.9, n.4., p.108-123, 2018.

BRASIL. Base Nacional Comum Curricular: educação infantil e ensino fundamental. Brasília: MEC, 2018.

BECHARA, E. Moderna gramática portuguesa. 37. ed. Rio de Janeiro: Lucerna, 2000.

BECHARA. Gramática escolar da língua portuguesa. 2. ed. Rio de Janeiro: Nova Fronteira, 2010.

CEREJA, W. R.; MAGALHÃES, T. C. Português: linguagens (1a ao 5a ano). 6. ed. São Paulo: Atual Editora, 2017a.

CEREJA, W. R.; MAGALHÃES, T. C. Português: linguagens - manual do professor (1aa ao $5 \underline{a}$ ano). 6. ed. São Paulo: Atual Editora, 2017b. 
FRANCHI, C. Criatividade e gramática. Trabalhos em Linguística Aplicada, Campinas, n.9, p.5-45, 1987.

FREIRE, P. Pedagogia da autonomia. 36. ed. São Paulo: Paz e Terra, 2007.

HALLIDAY, M. A. K.; HASAN, R. Cohesion in english. London: Longman, 1976.

HALLIDAY, M. A. K.; MATTHIESSEN, C. M. I. M. Halliday's introduction to functional grammar. 4. ed. New York: Routledge, 2014.

LIBÂNEO, J. C. A formação de professores no curso de Pedagogia e o lugar destinado aos conteúdos do Ensino Fundamental: que falta faz o conhecimento do conteúdo a ser ensinado às crianças? In: SILVESTRE, M. A.; PINTO, U. A. (orgs.). Curso de pedagogia: avanços e limites após as Diretrizes Curriculares Nacionais. São Paulo: Cortez, 2017, p.49-78.

MAGALHÃES, T. G.; LACERDA, A. P. O. Concepções e práticas de oralidade na escola básica na perspectiva dos docentes. Horizontes, Itatiba, v.37, p.1-23, 2019.

MARCUSCHI, L. A. Produção textual, análise de gêneros e compreensão. São Paulo: Parábola editorial, 2008.

MENDONÇA, M. R. S. Análise linguística: refletindo sobre o que há de especial nos gêneros. In: SANTOS, C.F.; MENDOÇA, M.; CAVALCANTE, M. C. B. (orgs.). Diversidade textual: os gêneros na sala de aula. Belo Horizonte: Autêntica, 2007, p.73-88.

SANTOS, C. F.; MENDONÇA, M.; CAVALCANTE, M. C. B. O trabalho com gêneros por meio de projetos. In: SANTOS, C. F.; MENDOÇA, M.; CAVALCANTE, M. C. B. (orgs.). Diversidade textual: os gêneros na sala de aula. Belo Horizonte: Autêntica, 2007, p.115-132.

SIGILIANO, N. S.; SILVA, W. R. Diagnóstico de propostas de análise linguística em livros didáticos aprovados em programa oficial. In: MAGALHÃES, T.; GARCIA-REIS, A.; FERREIRA, H. (orgs.). Concepção discursiva de linguagem: ensino e formação docente. Campinas: Pontes Editores, 2017, p.19-40.

SILVA, W. R. Estudo de gramática no texto: demandas para o ensino e a formação do professor de língua materna. Maringá: Eduem, 2011.

SILVA, W. R. Letramento e fracasso escolar: o ensino da língua materna. Manaus: UEA Edições, 2012.

SOUZA, E. M. F.; LADEIA, R. T. L. R. O livro didático de língua portuguesa: um destaque discursivo para o ensino de gramática. Percursos Linguísticos, Vitória, v.8, n.18, p.58-74, 2018.

TRAVAGLIA, L. C. Gramática e interação: uma proposta para o ensino de gramática. 14. ed. São Paulo: Cortez, 2009. 
TRAVAGLIA, L. C. Gramática: ensino plural. 5. ed. São Paulo: Cortez, 2011.

\section{AGRADECIMENTOS}

Agradecemos a leitura cuidadosa realizada deste artigo pelos pareceristas anônimos da Revista Horizontes. Alguma fragilidade restante no texto é de nossa inteira responsabilidade. $O$ primeiro autor deste artigo agradece ao Conselho Nacional de Desenvolvimento Científico e Tecnológico pela bolsa de produtividade em pesquisa, que tem contribuído para as atividades científicas por ele desenvolvidas (CNPq 304186/2019-8).

Recebido em abril 2020.

Aprovado em janeiro 2021. 